\title{
The trend of price fluctuation in China and its influence on the living standard of residents -- take the first-tier city Shanghai as
}

\author{
an example \\ $Q u X u$ \\ Shanghai JiaoTong University, China \\ *Corresponding author: Qu Xu, 15821928016@163.com
}

\begin{abstract}
In recent years, price has showed the tendency of increasing. Taking Shanghai as an example, the trend of price changes is analysed in this paper, from which we learn the impact on residents' living standards. Firstly, this paper analyses the trend of rising speed, and then brings all kinds of reflections about the decline in living standards by rising prices, shown the situation of China's commodity price. Secondly, through the STATA software, a linear regression model probit is built to analyse data. Finally, it aims to arousing thinking about how to lead the rapid rise in prices, truly letting citizens enjoy the benefits of economic development.
\end{abstract}

Key words: rising prices; living standards; CPI, influence; Shanghai

\section{Introduction}

Nowadays, not only residents but also enterprises have felt the pressure of prices rising, while the gap between "real pain" CPI data and figure published by the Government Statistics Department has widen ${ }^{1}$.It also makes great attention from all walks of life to how to construct CPI data more objective, reflecting the reality of China's household consumption. Chen (2013) believes that attention paid about the price rises and price fluctuation of potential threat is very necessary. The fluctuation of prices is closely related to economic stability, social stability and people's living conditions ${ }^{2}$. Price fluctuation has become the core issue of economic development, and "stable price" has become one of the goals of macroeconomic regulation in various countries. Therefore, the study of price stability has theoretical and practical significance. 
After 2007, China's economy continues to grow at a rapid pace, but it is accompanied by a sustaining rise in prices. Meanwhile, Consumer Price Index (CPI) rose year on year in 2007, being the largest increase since 1997, which exceeded the international recognized warning line, as well as China's central bank's monetary policy objectives towards sustainable rapid economic growth. Tu (2011) believes that the reason for price changes is tight supply, rising costs and other aspects of supply-demand as well as the overall environmental impact at home and abroad (such as the restructuring of the domestic economy, foreign economic deterioration, and establishment of perfect regulations) ${ }^{3}$. The population of first-tier cities is large, and the impact of price for different income groups may bring the prominent contradiction. This paper takes Shanghai as an example of the rising prices, paying attention to more rapid price perception compared roughly a rising trend few years ago, which can cause more attention and thinking from all walks of life.

\section{The characteristic of rising price}

CPI (consumer price index) is referred to changes in macroeconomic indicators reflecting general household consumer goods and services purchased by the price level. In recent years, changes in CPI of Shanghai have broadly reflected trends in price changes, as shown in Table 1.

Table 1 - 2014-2016 Shanghai CPI year-on-year growth

\begin{tabular}{|c|c|c|}
\hline Index & Shanghai CPI & $\begin{array}{c}\text { Shanghai CPI year-on- } \\
\text { year growth }\end{array}$ \\
\hline 2014.07 & $1.03 \%$ & $3 \%$ \\
\hline 2015.07 & $1.2 \%$ & $2.6 \%$ \\
\hline 2015.10 & $1.3 \%$ & $2.4 \%$ \\
\hline 2015.11 & $1.5 \%$ & $2.4 \%$ \\
\hline
\end{tabular}

In rising prices and increasing pressure of living today,Shanghai as the representative of the first-tier cities can reflect Chinese rapid development at the same time bring inflation to the lives of ordinary people in pain. In some polls statistics, prices have risen too fast for several years leading residents concern mostly. The data also shows that the price brings the enormous pressure of life, but happiness of residents continues to reduce.

<2011 Shanghai people's livelihood development report> shows that in 2011, the overall livelihood evaluation index of Shanghai is only 58.51., belonging to the "below average" level. The basic monthly expenditure of low-income people increases by $20 \%$, Rigid expenditure's (food and health care) compression space is very limited, and more than $90 \%$ people feel a decline in living standards. The main reason of Chinese prices rising is that the price of 
agricultural products increases rapidly. This shows that more residents are concerned about these problems. Facing urgency to solve the concern of residents, the government needs to respond.

But the CPI index does not include price changes, which means losing an important measure of living standards ${ }^{4}$. Wages and prices are rising at the same time as the economy develops. However, the growth rate of wages is far below the average price rising speed. The gap between the two is the pressure of living. Lu (2012) believes that the food weight constituted China's CPI index is too high and the house purchasing price is not included in the CPI medium, so CPI data is not the real scientific reaction of consumption ${ }^{5}$.It may underestimate CPI, misleading the decision, being overly optimistic about the reality in the actual.

Considering price factors, Shanghai CPI trend varies. General judgment has two points: one is overall CPI will continue uptrend in recent years, a moderate increase probably; the other is because internal composition of CPI changes, structural fluctuations increase. The future needs scientific development of CPI, prediction of control objectives, key research of main influencing factors by paying attention to quantitative analysis.

\section{Positivism model}

In order to study the effect of rising prices for residents, this paper constructs a linear regression model with explanatory variables probit. x represents the price level (food prices, housing prices and income growth as the representative, the explanatory variable y (life feel) represents happiness. This study selects ordered probit (Ordered Probit Model) as the introduction of discrete mapping model, because the variable y are potential unobserved variables and explanatory variables of $\mathrm{y}^{*}$ vector $\mathrm{x}$ in the study have linear regression relation. The establishment of regression model:

$$
\mathrm{y}^{*}=+ \text { alpha }+\mathrm{X} \text { beta. }
$$

This is the source of data:

(1) Chinese comprehensive survey data (CGSS) survey results of 2003, 2006, 2012 and 2013 years;

(2) Released in Shanghai Bureau of the 2003, 2006, 2012 and 2013 year of vegetables (with vegetables, meat and poultry as the representative, with pork as the representative), food (mainly from rice, oil egg), fruit (apple, as the representative of the price);

(3) Statistical year-book of Shanghai in 2003, 2006, 2012 and 2013 prices . Shanghai area data of the four years are calculated in the model. The income and age from different life 
period are controlled. The life satisfaction of residents is named life feel and other variables roughly measure residents living level. By using STATA software, calculate the regression model.

Table 2 - Regression of life feel in income house price oil price vegetable price

\begin{tabular}{|c|c|c|c|c|c|c|}
\hline source & SS & $\mathrm{df}$ & MS & \multirow{2}{*}{\multicolumn{3}{|c|}{ Number of obs $=5415$}} \\
\hline model & 753.9 & 4 & 188.4 & \multicolumn{2}{|c|}{$F(4,5410)=316.72$} & \\
\hline residual & 3219. & 5410 & .595 & \multirow{3}{*}{\multicolumn{3}{|c|}{$\begin{array}{cc}\text { Prob }>F \quad=0.0000 \\
\text { R-squared } & =0.1897 \\
\text { Adj R-squared } & =0.1891 \\
\text { Root MSE } & =.77145\end{array}$}} \\
\hline total & 3973.64 & 5414 & .7339 & & & \\
\hline & 1 & & 565 & & & \\
\hline Life feel & Coef. & Std.Err & $\mathrm{t}$ & $\mathrm{P}>\mid \mathrm{t}$ & Conf. & Interval \\
\hline income & .1957 & .012 & 16.10 & 0. & 171898 & .2195813 \\
\hline House pri & .003042 & .00013 & -22.25 & 0. & .003310 & .0027746 \\
\hline Oil price & 1.94318 & .07203 & 26.98 & 0. & 1.80197 & 2.084395 \\
\hline _cons & 44.72 & 1.92 & 23.23 & 0. & 48.5034 & 40.95451 \\
\hline
\end{tabular}

Table 2 is OLS regression, we can find that income is positively related to happiness, and house price is negatively related to happiness. (unit house price is not significant).

The problem of rising prices continues high attention rate. The relationship related to residents' daily life closely. Vegetables, aquatic products, egg, pork, edible oil and other food prices and housing rents, residents living water prices rise sharply, resulting in a greater impact on low-income population. At the same time, in the background of rising prices, the actual deposit interest rate has become a "negative interest rate", and residents "pocketbook" has shrunk dramatically, at meantime middle income groups also suffer. The factor of promoting price rise still has a lot, and inflation pressure is still large. The price rise and slow growth of the income are two-way squeezing" affecting the livelihood of difficult groups" might further increase. The demands of "Increase wage income" increase. In the analysis of STATA data, it can be found that the value of personal income increase but the increase is small, especially compared with the rate of commodity price. So in the context of inflation expectations, more groups feel greater economic pressure.

Based on the above analysis of the empirical data from the Shanghai area, the differences among area were excluded in the regression model. Other explanatory variables include gender, age, education, nationality, marriage, gender reaction in different age and different ethnic groups have different attitudes towards price. The higher the level of education and 
income, the reaction degree of the effect on happiness is not obvious. Marital status will affect the price response of the residents. Generally married people on prices have deeper feelings. Data existing limitation is: first, because of the singly house price and relation to happiness in the data is a little; second, food prices are download from the Bureau website, only the average price per year, so the price variable contains less data packet, as well the lack of consistency and accuracy.

\section{Empirical results}

The limitations of the results cannot be denied. First from the provinces variables, this paper focuses on the study of the selected data (the Shanghai area). Shanghai, as a first-tier city, may also get a glimpse of Chinese situation. But in different provinces, there are still great differences. In the Midwest, prices rising shows no obvious. But rising trend still exists. Similarly, the income is growing but not very obvious. The geographical position and the degree of economic development differ from those in Shanghai, and shanghai has frequent economic trade with the domestic and foreign ${ }^{6}$. The development of Shanghai is fast, and it is easy to be affected by other factors of domestic and international economic fluctuations. The results of regression are following:

(1)From the perspective of gender and marital status, married women will have more intuitive and clear feelings about the rise in prices.

(2)From the perspective of the length of education, the person has high education period, higher working conditions and higher wages, will not be greatly influenced the experience of happiness by the price increase.

(3)From the age on the face of rising prices and the pressure of life, different groups have different responses. From the age level, 35-59 year-old have maximum inflation response.

(4) From the level of income, the family per capital is 100 per month or less, the life stress is the most serious. As the family monthly income increases, the degree of their life pressure is correspondingly decreasing.

(5)From year's income of residents and housing prices, residents need decades for accumulating money to have their own housing. Life pressure is greater.

Prices reflect the difference of various types of goods rising rate. It is not difficult to find, and in the era of media it can be heard everywhere related to public concerns even complain sound. But it seems that the government does not pay enough attention to the economic development ${ }^{7}$. In recent years, the growth rate has declined, but prices did not stop rising. The 
impact of rising, from a long-term and from overall state, will lead to negative interest rates and continued monthly expanding, so that residents' property is seriously diminished. In addition, the high prices will lead to the difficulties of life especially low income levels of groups ${ }^{8}$.

In the face of high prices, moderate and low level residents realize obviously the burden of life. The government can also do something in this area, such as constructing the macroeconomic early-warning system. As of now, the price subsidy policy has begun to take shape and have a certain effect.

\section{References}

1. Wang Guogang. The proportion of the weight of the chief food CPI should be down. China Economic Herald, 2008,(5): 7-8.

2. Chen Qunmin,Wu Yebai.Declaration,et al. 2011 Shanghai people's livelihood investigation report, scientific development, 2012,(3): 106-116.

3. Tu Jiaqi.On the current price rising structural characteristics and Countermeasures of economic perspective,2011,(26): 125-126.

4. Zhang Qing. Connotation and weight comparison of residential prices in Chinese and foreign CPI compositions. China economic times,2008,10-30.

5. Lu Lilan.CPI statistics and the residents feel the deviation of Southwestern. University of Finance and Economics. 2012.

6. Feng Yaojun.The effect of rising prices on the life of low-income residents in Shanghai.Statistics, science and practice,2011, (4): 20-22.

7. Wang Zhixiong, Zhen Mingxia, Qi Yeping et al. Basic judgment on current price situation in Shanghai: analysis of characteristics, factors and trends.Shanghai economic research, 2011,(2):105-112.

8. Shaanxi Province Price Bureau task group.Built vegetable garden rich food basket, promote the basic stability of vegetable prices - ten years, affecting our province vegetables .An empirical study on the factors of vegetable price fluctuation . Shaanxi development and reform,2013,(1): 29-32. 